\title{
New Approaches and Tools for Grazing Management
}

\author{
Emilio A. Laca \\ Author is Professor, Department of Plant Sciences, University of California, Davis, CA 95616 USA.
}

\begin{abstract}
Novel concepts and tools to promote progress in grazing science and management need to incorporate heterogeneity and nonlinear scaling of spatially and temporally distributed ecological interactions such as diet selection, defoliation, and plant growth. Traditional grazing management factors are number of animals, species and category of animals, spatial distribution of forage demand, and temporal distribution of forage demand. These traditional methods have been based on a paradigm that is static, assumes equilibrium conditions, and does not consider scaling issues, neither in time nor in space. Three related issues that can contribute to the progress in the understanding and management of grazing systems are spatial heterogeneity, eventdriven dynamics, and scaling effects. Spatial heterogeneity of species and defoliation determine pasture stability by modulating competition and response to heterogeneous defoliation. When pasture species are well mixed, livestock are less able to select their preferred diet. When species are separated into larger and more easily identifiable patches, the selected diet approaches the preferred one. Simultaneously, patchiness in pasture components and redistribution of nutrients by grazing can lend global compositional stability to grass-clover pastures. Grazing at high animal density can be studied using the paradigm of eventdriven dynamics. Several mechanisms suggest that grazing systems should have allometric spatial and temporal scaling in addition to the well-recognized allometric scaling of food requirements with body mass. Grazing system performance should scale allometrically with pasture size because both resource distribution and animal movements frequently have fractal properties. As pasture size increases, fewer hierarchical levels of grazing behavior are constrained, and the new spatial patterns introduce nonlinearity in the response to pasture size. Operant conditioning of foraging behavior, conditioned aversions, plant spatial pattern, pasture size and shape, timing and duration of grazing periods, and number of animals are discussed as precision tools to manage grazing systems.
\end{abstract}

\section{Resumen}

Los conceptos nuevos y las herramientas que promueven avances en el manejo y ciencia de pastoreo necesitan incorporar la heterogeneidad y los cambios de escala no lineales de interacciones ecológicas tales como selección de dieta, defoliación, y crecimiento de plantas. Los factores tradicionales de manejo son número de animales, especie y categoría, distribución espacial, y temporal de la demanda de forraje. Los métodos tradicionales de pastoreo se han basado en un paradigma que es estático, este asume condiciones de equilibrio y no considera los cambios de escala en espacio ni tiempo. La heterogeneidad espacial, la dinámica dirigida por eventos discretos, y los cambios de escala son tres fenómenos que pueden contribuir al progreso de entender y manejar sistemas pastoriles. La diversidad espacial de las plantas así como su defoliación determinan la estabilidad de los potreros mediante la modulación de la competencia y la respuesta a la defoliación. Cuando se mezclan las especies de los potreros, el ganado tiene menos oportunidad de seleccionar su dieta preferida. Cuando las especies están separadas en manchones fácilmente identificables, las dietas se aproximan a lo que los animales prefieren. Simultáneamente, la presencia de manchones de gramíneas y leguminosa, y la redistribución de nutrientes por el pastoreo puede darle estabilidad a las mezclas. Puede estudiarse el pastoreo con cargas altas como un evento extremo. Varios mecanismos indican que los sistemas pastoriles deberían tener una relación alométrica en tiempo y espacio, además de las conocidas relaciones alométricas de los requerimientos de forraje con el tamaño de los animales. El rendimiento de los sistemas pastoriles deber tener una relación alométrica con el tamaño de los potreros porque los recursos forrajeros y los movimientos de los animales tienen propiedades fragmentarias. A medida que se incrementa el área del potrero, un número menor de niveles de comportamiento es restringido y los nuevos patrones espaciales dan respuestas no lineales al área de los potreros. El condicionamiento instrumental del comportamiento de pastoreo, las aversiones condicionadas, el patrón espacial de especies forrajeras, el tamaño y forma de los potreros, el momento y duración de períodos de pastoreo, y por último, el número de animales se consideran como herramientas de precisión para el manejo de sistemas pastoriles.

Key Words: cattle, grazing systems, heterogeneity, scaling, sheep

\section{INTRODUCTION}

Research was partially funded by the Western Agriculture Research and Education Program grant SW06-038 and by the Kearney Foundation of Soil Science.

Correspondence: Emilio A. Laca, Dept of Plant Sciences MS1, University of California, Davis, CA 95616, USA. Email: ealaca@ucdavis.edu

Manuscript received 14 April 2008; manuscript accepted 25 February 2009.
Herbivory can have dramatic impacts on productivity, composition, and function of grassland and pasture ecosystems. Yet, our ability to manage these effects has reached limits set both by the traditional paradigms and by the set of factors selected to manage grazing systems. These paradigms assume that grazing, plant growth, and ecological interactions are uniform 
and vary continuously over space and time. Typical management factors considered are total and seasonal forage demand, animal density, and duration of grazing (Heitschmidt and Taylor 1991). Diet selection is represented as the proportion of each species grazed and it is thought to depend on the proportion of the species present in the pasture (Dumont et al. 2002). Preferred species are grazed more and potentially tend to decrease due to competitive interactions. The traditional paradigm used to develop most current grazing practices and to research plantanimal interactions ignored spatial heterogeneity and nonlinear scaling, although it did recognize the problem of heterogeneous use of large pastures (Vallentine 1990).

Research about grazing methods has focused on comparing methods defined at a global level, such as continuous vs. rotational grazing, whereas the performance of grazing systems can be determined by very specific details of how plants and animals function and interact in space and time (Weber et al. 1998). For example, a rotational system can promote homogeneity within paddocks and heterogeneity among paddocks, whereas the reverse can be true for continuous grazing. Paddocks in the rotation that happen to be ungrazed during the critical period of reproduction of an invasive weed will tend to become weedy, whereas those paddocks grazed when the weed is susceptible to defoliation will tend to be less weedy (DiTomaso et al. 2008).

Grazing systems are complex and vary in time and space in a manner that influences their dynamics. Grazing systems are subjected to expected and unexpected challenges, and their response and productivity can be dictated by discrete events more than by stable trends. This concept has been developed and explored in state-and-transition models (STM) for rangeland management (Westoby et al. 1989; George et al. 1992; Briske et al. 2005). Grazing systems, particularly in arid and semiarid regions, are characterized by wide temporal fluctuations, so singular events such as drought or fire can be more important than long-term trends.

The thesis of this paper is that we need a more practical data based approach to grazing management, instead of further development of global ecological theories and models of equilibrium or nonequilibrium dynamics. I briefly list and explore some of the techniques that show promise to manage pasture composition and livestock diets. A more thorough review of factors that determine livestock diets is provided by Soder et al. (2009). I focus on outlining concepts and tools to further the progress in grazing science and management by incorporating scaling of spatially and temporally distributed ecological interactions such as herbivory, plant growth, and competition.

\section{TRADITIONAL GRAZING METHODS}

In this paper, a grazing system is an agroecosystem or a natural system consisting of interacting abiotic conditions, soils, plants, and animals, including large herbivores. A grazing method is a specific temporal schedule of animal kinds and densities for each pasture in the grazing system. The main factors used to manage grazing systems and to describe grazing methods are stocking rate, stocking density, and herbage allowance (Scarnecchia and Kothmann 1982). Traditional grazing methods (TGM) are grazing methods that have received a name, such as rotational grazing, three-herd four-pasture, Santa Rita, continuous, rest-rotation, and strip-grazing (Vallentine 1990; Holechek et al. 1995).

Traditional grazing management factors are number of animals (usually expressed as a ratio of number of animal units per unit land area, e.g., stocking rate, stocking density), species and category of animals, spatial distribution of forage demand, and temporal distribution of forage demand (Heitschmidt and Taylor 1991). The central issue in TGM is to balance forage demand with supply. The traditional analysis was a graph showing the relationship between intake or secondary productivity per animal unit, per unit land area, and stocking rate. Usually, this balance is calculated on a yearly basis, and in some situations, it is calculated on a seasonal or monthly basis. On a yearly basis, total yearly forage demand cannot be less than yearly forage production multiplied by a forage utilization factor that accounts for forage wastage and maximum utilization allowable.

More sophisticated methods such as The Grazing Manager (Kothmann and Hinnant 1994) prescribe frequent monitoring of the amount of forage available to update forecasts based on calculations of forage demand and supply. More precisely, the temporal integral of forage demand corrected by a utilization factor cannot be greater than the integral of forage production plus initial reserves. This method is superior because it adheres to a continuous feedback and forecasting system that must lead to a balance between forage supply and demand. Frequent assessment of forage availability and feedback to forage demand should lead to proper adjustments in most conditions, regardless of the causes of the changes in supply and demand of forage.

Stocking rate has been identified as the most important factor determining the overall performance of grazing systems, including productivity, sustainability, and composition of the vegetation (Hart et al. 1993b; Hickman et al. 2004). Nevertheless, productivity and pasture condition can be affected by grazing method. Rotational or short-duration grazing has resulted in better pasture condition in certain situations (Derner et al. 1994; Deregibus et al. 1995; Jacobo et al. 2006). Yet, recent analyses indicate that rotational grazing does not seem to consistently achieve results that differ much from continuous grazing (Briske et al. 2008). It is likely that the comparison of generic rotational vs. continuous grazing methods is too broad to have significant practical implications. Both grazing methods are defined in such a way that they easily can approach each other in terms of proximate causal factors such as frequency and intensity of defoliation of individual plants and tillers. The present paper proposes a shift from laxly defined generic grazing methods to precise grazing prescriptions that set narrow ranges for the most important factors determining the performance of grazing systems.

Regardless of grazing method, stocking rate, and other management factors, the grazing process can be thought of as a spatial-temporal series of bites removed from a set of plants by each animal. Along with the defoliation process, each animal effects a spatio-temporal series of urinations and defecations, and each plant experiences a spatio-temporal distribution of microenvironmental factors, including water, light, and nutrients.

From the point of view of the plant, what matters is the intensity and timing of defoliation, a concept that is well established in grazing science (Chapman et al. 2007). Perfor- 
mance of a grazing system is usually measured as some sort of explicit or implicit integration of functions of the series of bites, excretion, and environmental distributions, such as net primary or secondary productivity. Many different combinations of spatial-temporal sequences will map to the same overall performance values. Grazing methods can affect performance only through affecting the sequences, but I surmise that the mapping between traditional grazing tools and methods, and spatio-temporal sequences of defoliation, trampling, and excretion is weak and complex. This is a major problem in the science and management of grazing systems and it requires a novel definition of management tools that have stronger links to the resulting spatio-temporal patterns of bites and excretion.

In summary, traditional grazing management research has resulted in significant progress in the science and art of grazing. TGM stressed the need for a balance between forage demand and availability. TGM recognized the variety of animal selectivity and dietary habits of different kinds of livestock. Yet, TGM explored a limited set of tools to directly modify selectivity, spatial behavior, and diets of livestock. Although traditional methods identified the chief management factors, they tended to overlook the infinite combinations of these factors that are possible and became somewhat restricted to "named" options.

\section{RELEVANT QUESTIONS TOWARDS A NEW APPROACH}

It is relevant to ask where grazing research is going and where it should be going. Can we develop a solid conceptual model to generate and implement precision grazing prescriptions? Can we implement the necessary feedback systems and mechanisms to "navigate" with a degree of certainty towards various pasture management goals? What scales, what variables, and what types of grassland heterogeneity are relevant to understand and manage landscapes with large herbivores? What technologies are available and which ones need to be developed?

In this paper I first focus on three characteristics of grazing systems that can contribute to progress in the understanding and management of grazing systems. First is spatial heterogeneity. Current grazing management ignores spatial heterogeneity of plant growth and defoliation, particularly at scales smaller than $10^{2} \mathrm{~m}$. Second is event-driven dynamics. Most methods and assessments still emphasize results under equilibrium or trend conditions, whereas in many systems there is no equilibrium. The behavior of grazing systems can be better understood as a series of responses to specific events at certain times than as a tendency to reach equilibrium or a specific state, as in STM. Third, I consider scaling effects. Except for the effects of body size on energy demand, current grazing management ignores all other potentially nonlinear scaling effects such as pasture size, herd size, and grazing period. After considering the characteristics of grazing systems, I list a series of new tools to enhance the management of grazing systems.

\section{HETEROGENEITY}

Resource heterogeneity is a key factor determining the dynamics of large herbivores and the landscape (Laca 2008).
Heterogeneity makes grazing systems deviate from predictions based on models that assume spatial and temporal homogeneity (Parsons and Dumont 2003). Spatial variability in the composition and amount of herbage affects animal behavior and the relationship between average herbage mass per unit area and animal performance. In turn, grazing behavior and selectivity can generate, maintain, or reduce heterogeneity in pastures. In this section I analyze how pasture heterogeneity affects grazing behavior and animal performance, and how grazing behavior affects pasture composition and productivity. My goal is to illustrate- not to review-how pasture heterogeneity can explain the variability of results of grazing methods, and how it can be used to manage grazing systems.

Spatial heterogeneity can affect grazing systems through three independent mechanisms: 1) nonlinearity of responses to local and instantaneous conditions, 2) selectivity, and 3) change of functional form of local responses due to global conditions (Laca 2008). Intake and productivity respond to forage quantity and quality in a nonlinear concave-down fashion well known as "diminishing returns." This implies that-without selectivity-intake and productivity should be lower in a heterogeneous environment than in one that is homogeneous and has the same average characteristics. By selecting the better patches, animals can partly compensate for the effect of heterogeneity. Further compensation can take place if animals change their behavior at the local scale in response to global conditions, for example by increasing the number of bites per feeding station in response to a reduction in the average amount of forage available per unit area.

\section{Heterogeneity and Diet Selection}

Livestock respond to multiple scales of resource heterogeneity. Edwards et al. (1994) studied the selectivity of sheep for cereal over straw pellets. Sheep selected a greater proportion of the preferred cereal pellets when the pellets were larger and when the sheep had not been fasted. Sheep also were more selective when "good pellet patches" (bowls containing $105 \mathrm{~g}$ of cereal and $45 \mathrm{~g}$ of straw pellets) were in large clusters than when not clustered and interspersed with individual "bad" patches (45 g of cereal and $105 \mathrm{~g}$ of straw pellets). Overall, this work provided experimental support to the hypothesis that larger spatial separation between dietary options and higher satiation promote greater selectivity. Sheep selected at the level of pellets, bowls, and clusters.

The ability of livestock to select at various scales was documented in several studies with realistic grazing conditions. Ganskopp and Bohnert (2006) created 14-ha pastures where half of the area was of high quality and low herbage mass (termed "conditioned" crested wheatgrass, Agropyron desertorum [Fisher ex Link] Schultes), and the other half was of low quality and high herbage mass (senescent crested wheatgrass; $58 \pm 0.6 \%$ vs. $47 \pm 1.8 \%$ in situ dry matter digestibility, $202 \pm 38 \mathrm{~kg}$ vs. $543 \pm 7 \mathrm{~kg}$ dry matter $\cdot \mathrm{ha}^{-1}$ ). Cows spent two-thirds of the grazing time on the high quality side of the pasture, thus evincing ability to perceive and select at a scale of tens of hectares. WallisDeVries et al. (1999) explored the effect of scale of heterogeneity by creating tall low quality and short high quality patches Setaria lutescens (Weigel) Hubb. that were $2 \times 2$ (fine resolution) or $5 \times 5$ (coarse resolution) m randomly 
arranged in 0.08-ha pastures. Steers took $93.3 \pm 3.9 \%$ and $78.4 \pm 5.2 \%$ of the bites from the short patches in the coarse and fine resolution treatments, respectively.

As the degree of spatial mixing declines, i.e., when species are separated into larger and more easily identifiable patches, ruminants can select the diets they prefer more easily (Rutter 2006). Rutter et al. (2005) created pastures with white clover and ryegrass strips at four scales of interspersion, $108 \mathrm{~cm}, 36 \mathrm{~cm}$, $12 \mathrm{~cm}$, and fully mixed. Yearling beef heifers were able to select their preferred $60 \%$ clover in strips that were 36 and $108 \mathrm{~cm}$ wide. In narrower strips and the mixed sward, percentage of clover in the diet dropped to less than $38 \%$. Smaller animals also are affected by scale of heterogeneity. Sheep prefer to graze on grass instead of heather patches, and the degree of selectivity for grass decreased as the distribution of grass in a heather matrix changed from one large to four medium to 12 small patches of grass covering one-sixth of the total area (Clarke et al. 1995). A study by Marotti et al. (2002) showed that diet composition and daily intake of sheep can be manipulated by the spatial arrangement of dietary choices. Sheep grazed four treatments: pure ryegrass, pure clover, a mixed pasture, and a pasture with half of the area seeded to each species. Sheep achieved greater intake rate and daily intake in pure clover than in grass. Intake rate was greater in the pasture with separate patches of grass and clover than in the mixed sward.

\section{Heterogeneity and Pasture Composition}

The spatial distribution of the different pasture species determines the balance between intra- and interspecific competition and interactions. Individual plants create an "ecological field" around them where they potentially influence other plants (Walker et al. 1989). The radius of the ecological field is in many respects proportional to the height of the plant; thus, most pasture plants have a radius of influence that is less than $0.5 \mathrm{~m}$ with most of the interactions taking place within $0.2 \mathrm{~m}$. When patch diameter is more than $1 \mathrm{~m}$, most plants interact with plants of the same species instead of other species. Thus, spatial structure of the plant community can be used not only to regulate animal behavior, but also to modulate the interaction between species. This is a relevant management opportunity, given that maintaining desirable pasture composition and livestock diets are major issues in pasture management.

From the point of view of pasture stability, heterogeneity is not necessarily a negative characteristic of grazed systems. Schwinning and Parsons (1996) explored the effects of heterogeneity on model grass-legume pastures by including spatial heterogeneity in botanical composition, nitrogen inputs, and livestock selectivity. When spatial heterogeneity was ignored, pasture composition exhibited large fluctuations due to lags in the transfer of nitrogen to the grass and competitive exclusion of the legume by the grass after it acquired the nitrogen. However, when spatial heterogeneity of grass and legume content was incorporated, the pasture-scale fluctuations were minimized. The main mechanism for sustained coexistence was that random deposition of urine created a variety of patches in different stages of the exploitation cycles that continued to take place at the patch level. Degree of heterogeneity in pasture composition affected the dynamics of nitrogen transfer from legume to grass.
Plant heterogeneity and the specific details of plant interspersion also control apparent competition among species. Apparent competition exists when density of one species negatively affects performance of a second one through increases of a common predator. Clarke et al. (1995) observed that sheep consumed more heather, the less preferred species, when it was near edges with grass patches. As a result, finer interspersion of heather and grass resulted in sheep diets containing a greater proportion of heather and on greater overall grazing impact on heather (Hester et al. 1999). Dumont et al. (2002) found very similar results in a controlled experiment where different total areas of preferred ryegrass (Lolium perenne L.) were distributed as patches of various sizes in a matrix of fescue (Festuca arundinacea Schreb.). Fescue within $1 \mathrm{~m}$ of the edges of ryegrass patches was consumed more than further away.

Thus, it is clear that not only the proportion of species but also their degree of interspersion controls two main mechanisms that drive plant community dynamics. Most studies of plant community dynamics and grazing completely ignored the spatial distribution of species at the spatial scales at which competition and apparent competition take place. I surmise that it is likely that much of the unexplained variation in results was due to differences in the spatial pattern of plants.

\section{Heterogeneity and Plant Growth}

Traditional models of grazing system dynamics assumed that defoliation and growth were spatially homogeneous processes (Noy-Meir 1975), but in reality, grazing generates heterogeneity because it is a discrete process in space and time. Herbage mass per unit area is reduced almost instantaneously by removal of the top half of the canopy by each bite. Therefore, grazing generates a mosaic of interspersed tall and short patches that are functionally different. Grazed plants have reduced growth rates because of a limitation in leaf area, but they will eventually develop a canopy of young leaves that have a high photosynthetic capacity. Ungrazed areas maintain high leaf area but also have older leaves with lower potential assimilation rate. Because growth is nonlinearly related to herbage mass, total pasture growth depends on the specific spatial distribution of grazed and ungrazed areas (Schwinning and Parsons 1996; Parsons et al. 2001). The effects of heterogeneity and selectivity on the dynamics of pasture growth and grazing are illustrated in Figure 1.

The spatial distribution of bites can further affect pasture growth by determining the results of competitive release, a phenomenon usually not contemplated in models of heterogeneous grazing. Competitive release is the response of surrounding plants when competitors are removed or reduced (Jutila and Grace 2002). When herbage is removed by a bite, the surrounding plants have the potential to experience competitive release, and thus to partially compensate growth rate per unit area for the removal of foliage. However, the impact of defoliation and potential for compensation depends on the spatial pattern of defoliation. For example, when leaf area is reduced by grazing, undefoliated plants receive more light only if defoliated and undefoliated areas are finely interspersed. When defoliation takes place in large and discrete patches, few undefoliated plants experience competitive release, and global productivity declines. 

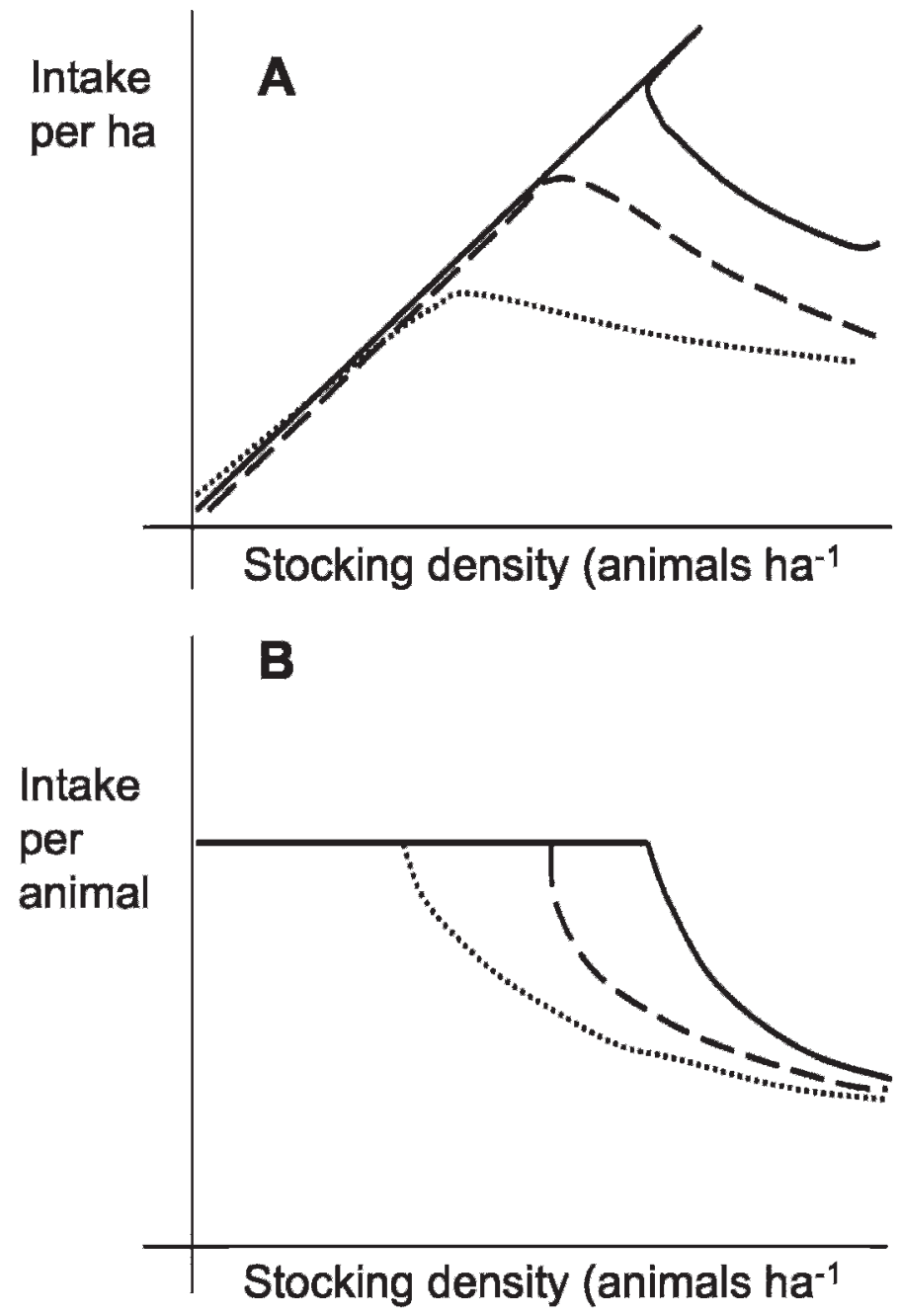

Figure 1. Modeled effect of stocking rate and heterogeneity on forage intake $\mathbf{A}$, per unit of land and $\mathbf{B}$, per animal. Solid line: homogeneous growth and grazing pattern as assumed by a nonspatial model; dashed line: spatial model that incorporates the heterogeneity of plant mass per unit area created by unselective grazing and its effects on growth; dotted line: same as dashed line but with partial selection against tall patches. Based on Parsons et al. (2001).

\section{EVENT-DRIVEN DYNAMICS}

Traditional grazing and management methods are based on assumptions of homogeneity and continuity of grazing in space and time (Briske et al. 2005). STM of ecosystem dynamics (Westoby et al. 1989; George et al. 1992) superseded the temporally continuous models, but they have not been translated into new grazing methods. Even the novel STM approach tends to emphasize long-term and large-scale mechanisms and decisions. Although STM provide an empirical and conceptual basis to incorporate discrete dynamics, thresholds, and landscape-scale heterogeneity in grazing decisions, they need further development into an expanded set of tools and concepts.

Jentsch et al. (2007) emphasized the need for "eventfocused" instead of "trend-focused" research to address impacts of climate change. Climate change is expected to cause more frequent extreme events that are characterized by statistical extremity, abruptness relative to the life span of the organisms affected, and consequences that are disproportionate to the event's short duration. In the context of management of grazing systems, management practices and unpredictable events can be investigated as "extreme" events. For example, a reduction of herbage mass of $50-70 \%$ over the course of a few days of high-density grazing is certainly an extreme event to the rangeland ecosystem. The timing and spatial location of the defoliation can have as much or more relevance than the long-term pattern of rotational grazing on the future botanical composition and productivity of the pasture.

Opportunistic management has long been identified as a potentially rich approach to grazing management. The approach identifies thresholds of pasture state and events that can push the system across the thresholds, thus generating nonlinear dynamics. STM and opportunistic management approaches have listed generic types of events or management actions that can be used to modify the state of grazing systems. The typical factors listed are drought, favorable rainfall, fire, grazing intensity, and "management prescriptions." In agreement with opportunistic management, this paper advocates the identification of thresholds and states where tactical manipulations can have dramatic impacts, but I emphasize the need to create a richer and more sophisticated toolbox of manipulations than can be tested and/or prescribed in any single grazing system. Some of these tools are explained below.

\section{SCALING EFFECTS}

The term "scaling" also has multiple uses and definitions. I emphasize the meaning that refers to using information obtained with a particular scale to derive characteristics of the system for a different one. Observation scale is the combination of three quantities: support, resolution, and extent (Skoien and Bloschl 2006). Support is the dimension of one sample, e.g., the area and volume of a soil core. Resolution is the minimum distance between sampling sites or cores, and extent is the maximum distance between samples, e.g., length of the transect. Scale can change by changes in one, two, or all three components. One of the major challenges of scaling is to design experiments and models to estimate landscape values for large extents based on observations and mechanisms in smaller extents, usually termed "up-scaling."

Scaling is particularly important to understand why grazing systems with the same values for descriptors such as stocking rate and stocking density can differ in performance. For example, TGM implicitly assume that the dynamics and functioning of a grazing system with 10 cows in 10 ha for $200 \mathrm{~d}$ to be the same as a grazing system with 1000 cows in 1000 ha for $200 \mathrm{~d}$, or with 500 cows in 1000 ha for $400 \mathrm{~d}$. All three situations would be classified as continuous grazing with the same stocking rate; the first two situations are identical in all traditional indices that can be calculated to describe grazing methods. Yet, several reasons discussed below make the situations dissimilar.

First, system performance is hypothesized to scale allometrically with pasture size because of the fractal nature of resource distribution (Milne et al. 1992) and animal behavior. This scaling refers to the relationship between grazing system performance and pasture or herd size, not body size. Strictly defined, a fractal 
distribution exhibits self-similarity: any subarea has the same structure and pattern as the whole area. Heterogeneity remains constant across scales. Natural fractals can exhibit changes in the degree of heterogeneity across scales. In general, resources with fractal distributions have densities that decline as the scale used to measure them increases (Ritchie 1998). The relationship between forage density and scale is a power law where the exponent is the fractal dimension; thus, there is an allometric scaling between resource density and area.

As pasture size increases, particularly in natural grasslands, the variety and heterogeneity of resources available to the herd increase (O'Neill et al. 1991), even if the global average remains the same. Livestock distribution in rangelands has fractal properties (E. A. Laca, unpublished data, 2008), most likely as a result of both the distribution of resources and the behavioral processes involved not only in diet selection while grazing, but also in social interactions, thermal regulation, and drinking. Cattle are able to closely track the spatial distribution of desirable food rewards across scales from $10^{1}$ to $10^{-1} \mathrm{~m}$. In foraging arenas with fractal feed distribution, cattle exhibited the highest efficiency of search, which was achieved by matching search paths to the nested scales of food distribution down to a resolution of $10^{-1} \mathrm{~m}$ (Laca and Ortega 1995). Thus, it is reasonable to expect that as pasture size increases while keeping stocking rate, stocking density, and herbage availability constant, spatial selectivity will increase. In larger pastures, larger areas will be completely ungrazed as livestock impose an effective stocking rate greater than the nominal rate in the preferred subarea of the pasture. Therefore, as pasture size increases, the relationship between nominal stocking rate or density and performance becomes a poorer description of the actual level at which plants and animals interact.

Second, the 10-fold change in pasture size interacts with spatio-temporal scales imposed by animal behavior. In the first situation described above, where pasture size is 10 ha, every cow of the herd can easily explore and interact with most of the pasture area in one day, whereas in the second situation, individual animals can only explore a fraction of the whole area per day. Considering that from the point of view of plants, grazing is an episodic process discrete in space and time (Parsons and Dumont 2003), the interaction between pasture size and spatial behavior can result in completely different performance in the two systems, most likely with the large pasture exhibiting much greater spatial heterogeneity and reduced performance per unit area.

Finally, the third situation differs in stocking density, but more importantly, it crosses the temporal scale imposed by the yearly cycles of herbage production, because the grazing period is $400 \mathrm{~d}$. This exaggerated example makes it obvious that time is not a substitute for space, but traditional indices for describing grazing methods use this substitution freely, albeit for periods shorter than one year. However, one must consider that yearly cycles are not the only types of cycles or renewal period for resources.

Scaling effects depend on the interaction between resource heterogeneity and body size. Prins and Langevelde (2008) showed that suitability of a landscape composed of patches with different nutritional characteristics depends on the interaction between body size and distance between patches. In their study, nutritionally complementary patches were rather large and could be separated by many kilometers. Large ruminants can exploit and survive in landscapes with complementary patches that are far apart. They can exploit coarse grain heterogeneity because of their mobility and large rumens, which allows the animals to mix dietary components that are far from each other. Smaller ruminants are able to exploit fine scale heterogeneity, but they are less able to buffer coarse scale patches.

\section{TOOLS FOR PRECISION GRAZING}

Grazing systems are complex and not fully predictable on a mechanistic basis. Therefore, we must use a good combination of mechanistic understanding and empirical results. Animal, pasture, and rangeland sciences already have revealed several potential tools to modulate the interaction of livestock with the landscape. We should manipulate not only herd type, animal density, and grazing period, but also animal behavior and the spatial distribution of pasture characteristics such as botanical composition and herbage mass. Information technology has the potential to provide rich real-time monitoring of animals and plants. The rich information about animal behavior and location can be used in closed-loop feedback systems. As cost of information and control systems continue to decline and price of energy continues to increase, different tools and management options will be feasible and optimal. In this section I list and briefly describe several grazing management factors to be further explored in theory and practice.

\section{Operant Conditioning and Food Search}

Livestock can be trained to perform tasks by using positive and negative reinforcement. In addition to being able to learn when and where food rewards will be available, livestock can use spatial memory and they can adapt food-searching patterns to match the patterns of food distribution in space and time (Edwards et al. 1996; Laca 1998; Dumont et al. 2002; Hewitson et al. 2005). Animals readily associate sounds and visual stimuli with food rewards, and will approach feeding areas when the stimuli are presented. Therefore, it should be possible to develop systems with specific food reward schedules to direct animal movement in the landscape.

Edwards et al. (1996) and Laca and Ortega (1995) showed that sheep and cattle readily associate visual cues (clover sods and colored flags, respectively) with food rewards. Interestingly, when sheep had learned the locations of the food by experience, they first searched in locations where food was in previous experimental sessions, and then they used the visual cues. When cattle were exposed to a complex feeding arena where feed pellets were individually distributed on the ground, they ignored previous locations and immediately used visual cues to find the pellets. Edwards et al. (1997) further showed that sheep can learn to associate preferred food with either clover or ryegrass patches $(67 \times 41 \mathrm{~cm}$ sods of approx. $5-\mathrm{cm}$ tall herbage). Animals were able to distinguish the patches from a distance of up to $5 \mathrm{~m}$, and exhibited $84-86 \%$ success in identifying locations with the preferred food (cereal pellets hidden behind the cue provided by the herbage patch). Howery et al. (2000) trained steers to associate visual cues (traffic barricades and cones) with the location and quality of the food. Cued animals were more efficient at finding the preferred food, consumed more food per unit distance traveled, and spent more 
time feeding than uncued ones. These experiments demonstrate that food-searching behavior is susceptible to modification by using different types of visual cues and training schemes.

There are two main domains of spatial scales in behavior that need to be addressed by different approaches in order to control selectivity: small scale within feeding bout (bite, feeding station and patch) and large scale between feeding bouts (feeding site and camp). The main difference between these domains is their susceptibility to control by using point attractants and cognitive processes vs. distributed attractants/deterrents and affective processes such as learned flavor aversions. The two domains of scale of animal behavior interact with the spatial distribution of palatable and unpalatable plants, because when plants with different palatability are separate in the large scale, selectivity at the small scales, potentially controlled by conditioned aversions, also will result in large-scale patterns of spatial selection.

Whereas the selection of feeding sites and camps can be modified by using point attractants such as permanent or intermittently available feeds of high palatability (Bailey and Welling 2007), selectivity among patches, feeding stations, and bites needs to be addressed by changing the internal state of the animal, for example by modifying rumen function through supplementation, fasting, etc., or by conditioned flavor aversions (Villalba and Provenza 2009). The use of permanent or predictably located point attractants and its effectiveness has a long history in management, and it has been well researched (Vallentine 1990). Based on my research on food searching behavior of cattle, I proposed the use of point attractants with custom-designed spatio-temporal schedules of intermittent availability to elicit the desired combination of search and grazing behavior (Laca 1998). Initial research on temporal schedules of reinforcement to modify grazing pattern indicates that the method has potential, but further research is necessary (Distel et al. 2004).

\section{Conditioned Aversions}

Provenza (1996) fully incorporated the theory and practice of conditioned aversions into the realm of livestock behavior and grazing management. It is now clear that ruminant livestock have the ability to finely discriminate the different foods they consume, and that they develop conditioned taste aversion just like monogastric animals. Livestock can not only avoid consumption of toxic levels of a poisonous plant, but they can also regulate their intake of toxin and antidote even if these are in different areas of the pasture (Villalba and Provenza 2002). This provides a fertile ground to design management actions. For example, a research group at University of California at Davis successfully trained sheep not to eat grape leaves. The sheep are used to control weeds in vineyards (Morgan Doran, University of California, Davis, personal communication, June 2006). These results are encouraging because they suggest that through diet training, we could adjust the relative grazing pressure on many pasture components. A more complete review of the role of conditioned aversions in ruminant diets is presented in Provenza (1996).

\section{Spatial Pattern of Plants}

Spatial pattern of planting is an established management factor in silvopastoral systems (Sharrow 1991), where clustered trees promote the best balance between pasture and tree productiv- ity. By clustering trees, competition between trees and pasture is reduced, and the silvopastoral system provides patches that animals can select to satisfy various needs such as thermal comfort and forage. Spatial pattern of different kinds of herbage could be used to accomplish management of diet and space use by livestock.

Vertical distribution of species can be managed by breeding and selection of species and cultivars, and it can be further controlled by the schedule and intensity of grazing. Horizontal distribution can be controlled by cultural practices, particularly by the pattern of seeding or interseeding, by application of fertilizer or herbicides, and by breeding and selecting cultivars that form stable patches. Chapman et al. (2007) concluded that there is empirical and theoretical support for using spatially or temporally separated pasture compositions offered to grazers to control productivity, pasture composition, and environmental impacts of grazing systems. The reader is referred to Chapman et al. (2007) and references therein for a thorough review of the relationship between spatial pattern of pastures and livestock behavior.

\section{Timing and Duration of Grazing and Rest Periods}

Timing of grazing periods relative to the phenology of plant species can have dramatic effects on the botanical composition and productivity of pastures. In some grazing systems, it is possible to identify temporal windows when severe grazing events can have maximal impact. For example, medusahead (Taeniatherum caput-medusae [L.] Nevski) is an invasive annual weed characterized for having a late maturity relative to other grasses in the California annual grassland. If the grassland is grazed severely just before medusahead spikes emerge but after growing points have differentiated into reproductive structures, medusahead seed crop is dramatically reduced (DiTomaso et al. 2008). Desirable grassland species such as softchess and ryegrass are not damaged by the heavy grazing because they have earlier phenology and have already produced seed by the time medusahead flowers. Timing interacts with grazing duration and stocking density, because medusahead plants exhibit significant variation in timing of spike emergence (Fig. 2). Once a spike emerges, the probability that it will be grazed declines rapidly, because livestock avoid the coarse and sharp awns. Other factors being equal, long grazing periods with lower stocking densities are less effective because more tillers have a temporal window to flower and escape grazing.

Timing of the rest period can be as important as timing of the grazing, because the benefits of rest cannot be realized if it takes place during a time when the plant is phenologically incapable of growing or the environmental conditions limit growth. When there is not enough soil moisture for plants to grow, rest will have little impact beyond preventing physical damage to the plants. Thus, opportunistic timing of grazing and rest based on weather patterns within the season can be used to maximize the impact on certain species.

Fine-tuning of duration of grazing and resting periods can be used to modify the proximate causes of plant response to defoliation. For example, Gillen et al. (1990) studied the frequency and intensity of tiller defoliation in rotationally grazed systems with three grazing schedules consisting of three combinations of grazing and rest durations (on average these 

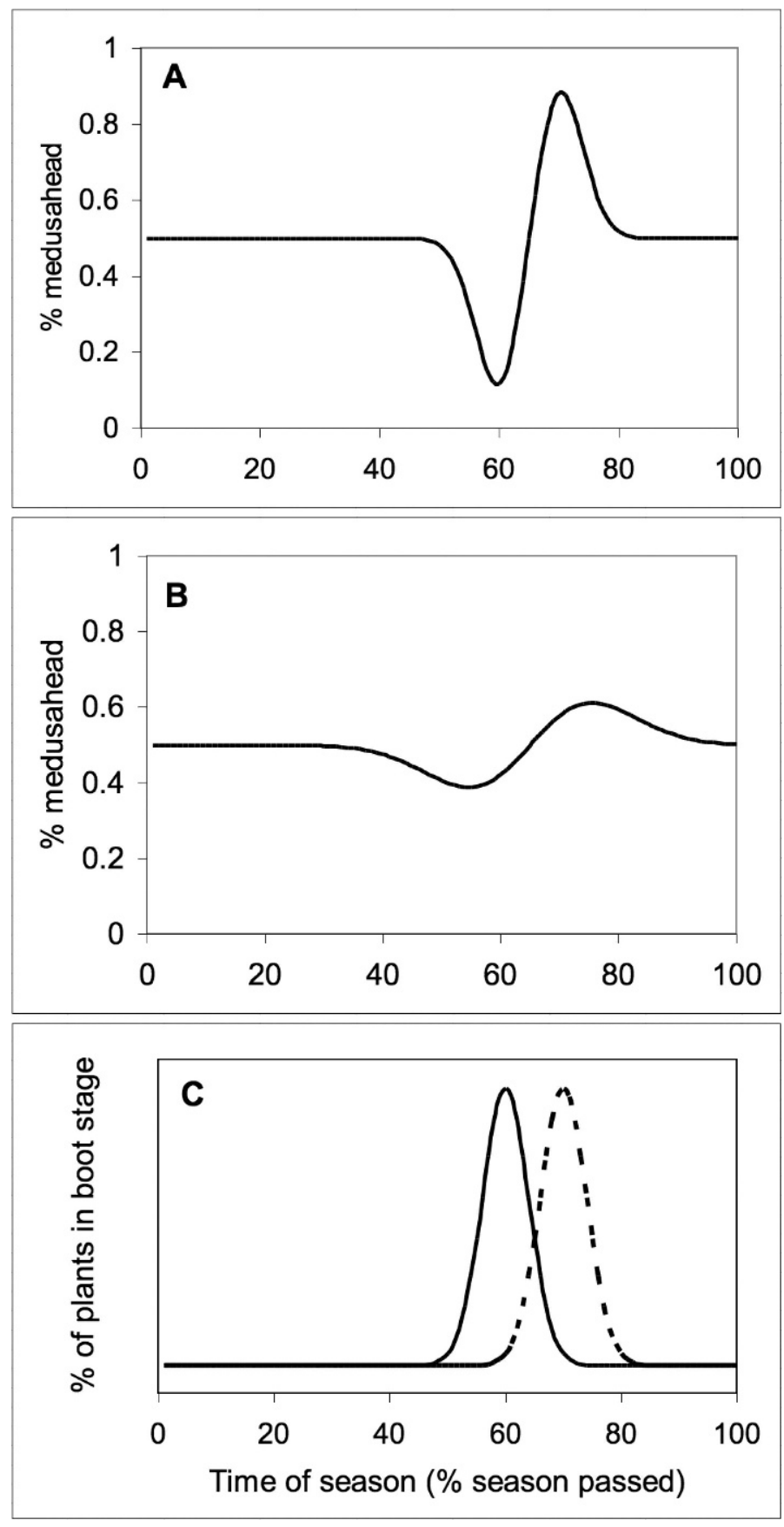

Figure 2. Hypothetical interaction between timing and duration of grazing to control medusahead. A, proportion of weed (medusahead) as a function of the date of beginning of a short (10-20 d) grazing period with high animal density. B, proportion of weed achieved in the following season as a function of the date of beginning of a long (40-60 d) grazing period with lower stocking density. C, phenology of medusahead (full line) and desirable forages (dashed line) as represented by the proportion of tillers in boot stage. In $\mathbf{A}$ and $\mathbf{B}$, the $\mathrm{x}$ axis represents the date of beginning of grazing. Grazing varies from promoting to controlling medusahead depending on its timing relative to phenological stages.

were $10 \mathrm{~d}$ and $67 \mathrm{~d}, 6 \mathrm{~d}$ and $44 \mathrm{~d}$, and $5 \mathrm{~d}$ and $33 \mathrm{~d}$ ) resulting in 2 , 3 , or 4 grazing cycles per season. Stocking density, stocking rate, number of grazing days per year, and pasture size were constant. Intensity of tiller defoliation and proportion of tillers ungrazed were not affected by treatments. Frequency of defoliation increased with the number of grazing cycles. This increase in defoliation frequency was larger for the less preferred Schizachyrium scoparium (Michx.) Nash, than for the more palatable Andropogon gerardii Vitman, which tended to equalize grazing impacts.

de Wolf et al. (2004) studied the effect of pasture size on botanical composition of rotationally grazed pastures while holding number of animals (seven ewes) and stocking rate constant. Pasture size ranged from 0.014 ha to 0.133 ha and it was compensated by increasing grazing duration from $1 \mathrm{~d}$ to $8 \mathrm{~d}$ per rotation. All pastures exhibited increasing proportion of the invasive creeping bentgrass (Agrostis stolonifera L.), and the natural seasonal tendency for white clover (Trifolium repens L.) to increase and ryegrass (Lolium perenne L.) to decline over the season. The increase in white clover (preferred by sheep) was inversely proportional to pasture size, whereas the increase in bentgrass was directly proportional to pasture size. The same total stocking rate distributed in shorter periods of high density grazing might have resulted in less avoidance of bentgrass and less selectivity for clover. The treatments explored in these studies hardly would be considered different grazing methods or strategies from the traditional point of view; yet, they had significantly different impacts on the grazing system.

\section{Pasture Size and Shape}

Hart et al. (1993a) determined that the differences between rotational and continuous grazing methods partially might be explained by the implicit difference in distance to water and pasture size. Level and uniformity of utilization did not differ between grazing methods when compared at the same pasture size and stocking rate. The continuous and rotational methods had equal pasture size ( $24 \mathrm{ha}$ ) but differed significantly in herd sizes (ca. 7 head vs. 50 head), and stocking densities while grazing (ca. 0.2 vs. 1.8 animal units $\cdot \mathrm{ha}^{-1}$ ). Daily gains of cows were significantly better in small than in large pastures, but daily gains and uniformity of herbage utilization were equal in rotationally and continuously grazed systems with equal stocking rate and small pastures.

The area used per animal per unit time can be manipulated by changing pasture size at a constant stocking rate. Hacker et al. (1988) studied the effects of pasture or herd size at constant stocking rate by having herd sizes equal to three heifers or steers per hectare in pastures of 1 ha, 2 ha, 4 ha, and 8 ha. Animals in the small pastures tended to behave always as a single herd, whereas subgroups with temporal differences in behavior formed in the larger pastures. Area used per animal while grazing increased from $4 \mathrm{~m}^{2}$ to $170 \mathrm{~m}^{2}$ from the smallest to the largest pasture, although the total area available per animal was constant $\left(3333 \mathrm{~m}^{2} \cdot\right.$ head $\left.^{-1}\right)$. The large increase partly might have been due to the formation of subherds. Presumably, the area used per animal would tend to reach a maximum that balances the animal's need to be in a herd (cohesive force) and its need to have an individual foraging space. This balance between nutritional and social needs was clearly demonstrated by Dumont and Boissy (2000) in an experiment in which sheep grazed attractive forage patches only when close to their social group or when accompanied by 
a subgroup. Shiyomi and Kubo (1982) found that intercow distance tends to be about $7 \mathrm{~m}$. Based on my experience observing grazing cattle, individuals rarely tolerate neighbors closer than $1 \mathrm{~m}$, and they rarely stray more than $30 \mathrm{~m}$ from the rest of the herd while grazing in large paddocks where fences do not limit spatial behavior within grazing bouts. Therefore, the unrestricted area "occupied" per cow at any given time has a maximum of ca. $150 \mathrm{~m}^{2}$, which is in agreement with the observations by Hacker et al. (1988).

Shape of pastures affects grazing behavior and the efficiency of use of forage (Sevi et al. 2001). Sheep utilize the herbage more efficiently in square than in rectangular paddocks of the same area. Walker and Heitschmidt (1986) found that subdividing a pasture into wedge-shaped paddocks converging at the watering point increased the number of trails with heavy trampling impact. There is little information on the effects of pasture shape when pastures have large areas similar to areas that could be used in commercial operations. Based on the hierarchical model of livestock behavior (Senft et al. 1987; Bailey et al. 1996), it is reasonable to hypothesize that the effect of pasture shape on use of space depends on the interaction between pasture size and native spatial heterogeneity of the resources. When resources are homogeneous, small pastures will constrain the natural radial pattern of grazing around watering points and "camps."

\section{Number of Animals}

Number of animals interacts with pasture size and length of grazing period to determine stocking density and the total amount of grazing demand or stocking rate on a site. By compensating stocking density with grazing time, various combinations of animal numbers and pasture sizes can be explored at a constant stocking rate. Number of animals in a pasture also determines the individual and herding behavior of animals. Few animals per pasture will tend to stay together, regardless of stocking density, whereas as the number of individuals increases, the tendency to form subherds with independent behavior also increases (Hacker et al. 1988). When 14-16 cows were grazed at a stocking density of 0.2 cows $\cdot \mathrm{ha}^{-1}$ in a 75 -ha pasture, they formed subgroups with two to six individuals and group size average was four cows (Harris et al. 2007).

The number of animals per pasture determines the dynamics of grouping behavior. Livestock form groups for many reasons related to balancing costs and benefits of grouping (Estevez et al. 2007). Individuals in groups incur costs due to competition for resources and space, but they obtain benefits of lower predation risk, thermoregulation, grooming, and cultural transmission of valuable information. Cattle can learn the location of food resources more quickly by following or observing herd members who have already found the resource (Bailey et al. 2000; Ksiksi and Laca 2000). The transmission of information about forage resources is probably one of the causes of nonlinear scaling of pasture use and productivity with pasture size, because herd foraging efficiency will be greater than the sum of the individual searches (Dumont and Hill 2004). Hamilton et al. (2007) documented nonlinear scaling of space use in human hunter-gatherers. As populations increase, they are more densely distributed in the landscape and individual home ranges overlap more. Larger populations are more effective at extracting resources from the environment, partly through the distribution of information. The net result is that instead of scaling linearly with group size, the population home range increases following a power law. Translated to a livestock herd, this suggests that as number of animals increases at constant stocking density, a smaller proportion of the pasture area available is effectively used per unit time, because animals have to spend less time to find the preferred patches. Hunt et al. (2007) documented this effect of paddock size in an experiment with large paddocks in Australia. As paddock size increased from $9 \mathrm{~km}^{2}$ to $34 \mathrm{~km}^{2}$ to $57 \mathrm{~km}^{2}$, the home range of cattle at a constant stocking rate declined as a proportion of the total area available. A reduction in home range as a proportion of paddock area means that home range increased with decreasing slope as paddock area increased, thus exhibiting allometric scaling.

Smaller pastures results in more even distribution of livestock, even if all pastures are continuously stocked with equal stocking density. However, when paddocks are large and instantaneous density is low, the improved distribution over space does not necessarily mean that there will be more even utilization of patches of different species. Diet selection integrates several hierarchical levels of behavior, each subject to different controls and stimuli. Therefore, scale-specific management tools are necessary to exert targeted control of selectivity (Hunt et al. 2007).

\section{IMPLICATIONS}

Traditional grazing methods are useful, but current environmental issues related to animal production and vegetation management, as well as progress in grazing science and practice, require an expansion of the basic concepts and toolbox. It is necessary to fully incorporate spatio-temporal heterogeneity of supply and demand of forage into dynamic models and methods. A review of the literature provides strong support for the following recommendations for grazing research and management:

1. Use adaptive management systems where inputs and decisions are integrated with monitoring at various temporal and spatial scales. Management decisions constantly should be updated on the basis of responses to previous actions by the specific system being managed. This approach can be particularly useful where we lack theories to generate good predictions, and to formally incorporate the expected deviation of specific systems from the average responses expected on the basis of theories or empirical results obtained elsewhere.

2. Develop systems to train animals to respond to visual and aural stimuli to control their large-scale selection of spatial locations. Schedules of stimuli and rewards can be easily programmed in a static manner or developed into real-time behavioral feedback systems, where rewards and stimuli are constantly updated in response to animal behavior.

3. Continue development of diet training systems. This is a well-developed field and can continue to improve by facilitation of animal training and reinforcement. 
4. Fully incorporate multiple scales of measurement in grazing research. A multiscale approach will yield clearer results by reducing the chances of missing the scale at which grazing methods affect the performance of grazing systems.

5. Develop grazing research programs that de-emphasize traditional methods, and emphasize discovery of those factors that actually might be controlling performance of grazing systems. For example, quantify the effects and interactions of pasture size, pasture shape, schedule of grazing and resting periods, number of animals, animal density, stocking rate, vegetation mass and heterogeneity, and phenology.

6. Generate grazing prescriptions based on mechanistic models complemented by empirical feedback methods and real-time information. Information and wireless technologies are widespread and will probably become inexpensive enough to justify their use in grazing systems relatively soon. Such systems will open a new era in natural resource management.

\section{LITERATURE CITED}

Balley, D. W., J. E. Gross, E. A. Laca, L. R. Rittenhouse, M. B. Coughenour, D. M. Swift, And P. L. Sims. 1996. Mechanisms that result in large herbivore grazing distribution patterns. Journal of Range Management 49:386-400.

Balley, D. W., L. D. Howery, and D. L. Boss. 2000. Effects of social facilitation for locating feeding sites by cattle in an eight-arm radial maze. Applied Animal Behaviour Science 68:93-105.

Bailey, D. W., And G. R. Welling. 2007. Evaluation of low-moisture blocks and conventional dry mixes for supplementing minerals and modifying catle grazing patterns. Rangeland Ecology \& Management 60:54-64.

Briske, D., J. Derner, J. Brown, S. Fuhlendorf, R. Teague, K. Havstad, R. Gilllen, A. Ash, and D. W. Willms. 2008. Rotational grazing on rangelands: reconciliation of perception and experimental evidence. Rangeland Ecology \& Management 61:3-18.

Briske, D. D., S. D. Fuhlendorf, and F. E. Smeins. 2005. State-and-transition models, thresholds, and rangeland health: a synthesis of ecological concepts and perspectives. Rangeland Ecology \& Management 58:1-10.

Chapman, D. F., A. J. Parsons, G. P. Cosgrove, D. J. Barker, D. M. Marotti, K. J. Venning, S. M. Rutter, J. Hill, And A. N. Thompson. 2007. Impacts of spatial patterns in pasture on animal grazing behavior, intake, and performance. Crop Science 47:399-415.

Clarke, J. L., D. Welch, and I. J. Gordon. 1995. The influence of vegetation pattern on the grazing of heather moorland by red deer and sheep. 1. The location of animals on grass heather mosaics. Journal of Applied Ecology 32:166-176.

Deregibus, V. A., E. Jacobo, and A. Rodríguez. 1995. Improvement in rangeland condition of the flooding pampa of Argentina through controlled grazing. African Journal of Range and Forage Science 12:92-96.

Derner, J. D., R. L. Gillen, F. T. McCollum, and K. W. Tate. 1994. Little bluestem tiller defoliation patterns under continuous and rotational grazing. Journal of Range Management 47:220-225.

de Wolf, P., R. P. O. Schulte, and E. A. Lantinga. 2004. A note on the effects of paddock size on the white clover content of swards grazed by sheep. Irish Journal of Agricultural and Food Research 43:103-107.

Distel, R. A., P. M. Soca, M. W. Demment, and E. A. Laca. 2004. Spatial-temporal arrangements of supplementation to modify selection of feeding sites by sheep. Applied Animal Behaviour Science 89:59-70.

Ditomaso, J. M., G. B. Kyser, M. R. George, M. P. Doran, and E. A. Laca. 2008. Control of medusahead (Taeniatherum caput-medusae) using timely sheep grazing. Invasive Plant Science and Management 1:241-247.
Dumont, B., And A. Bolssy. 2000. Grazing behaviour of sheep in a situation of conflict between feeding and social motivations. Behavioural Processes 49:131-138.

Dumont, B., P. Carrere, and P. D’Hour. 2002. Foraging in patchy grasslands: diet selection by sheep and cattle is affected by the abundance and spatial distribution of preferred species. Animal Research 51:367-381.

Dumont, B., and D. R. C. Hill. 2004. Spatially explicit models of group foraging by herbivores: what can agent-based models offer? Animal Research 53: 419-428.

Edwards, G. R., J. A. Newman, A. J. Parsons, and J. R. Krebs. 1994. Effects of the scale and spatial-distribution of the food resource and animal state on diet selection—an example with sheep. Journal of Animal Ecology 63:816-826.

Edwards, G. R., J. A. Newman, A. J. Parsons, and J. R. Krebs. 1996. The use of spatial memory by grazing animals to locate food patches in spatially heterogeneous environments: an example with sheep. Applied Animal Behaviour Science 50:147-160.

Edwards, G. R., J. A. Newman, A. J. Parsons, and J. R. Krebs. 1997. Use of cues by grazing animals to locate food patches: an example with sheep. Applied Animal Behaviour Science 51:59-68.

Estevez, I., I. L. Andersen, and E. Naevdal. 2007. Group size, density and social dynamics in farm animals. Applied Animal Behaviour Science 103:185-204.

Ganskopp, D., AND D. BohneRT. 2006. Do pasture-scale nutritional patterns affect cattle distribution on rangelands? Rangeland Ecology \& Management 59: 189-196.

George, M. R., J. R. Brown, and W. J. Clawson. 1992. Application of nonequilibrium ecology to management of mediterranean grasslands. Journal of Range Management 45:436-440.

Gillen, R. L., F. T. McCollum, and J. E. Brummer. 1990. Tiller defoliation patterns under short duration grazing in tallgrass prairie. Journal of Range Management 43:95-99.

Hacker, R. B., B. E. Norton, M. K. Owens, and D. O. Frye. 1988. Grazing of crested wheatgrass, with particular reference to effects of pasture size. Journal of Range Management 41:73-78.

Hamilton, M. J., B. T. Milne, R. S. Walker, and J. H. Brown. 2007. Nonlinear scaling of space use in human hunter-gatherers. Proceedings of the National Academy of Sciences of the United States of America 104:4765-4769.

Harris, N. R., D. E. Johnson, N. K. McDougald, and M. R. George. 2007. Social associations and dominance of individuals in small herds of cattle. Rangeland Ecology and Management 60:339-349.

Hart, R. H., J. Bissio, M. J. Samuel, and J. W. Waggoner. 1993a. Grazing systems, pasture size, and cattle grazing behavior, distribution, and gains. Journal of Range Management 46:81-87.

HaRt, R. H., S. Clapp, and P. S. Test. 1993b. Grazing strategies, stocking rates, and frequency and intensity of grazing on western wheatgrass and blue grama. Journal of Range Management 46:122-126.

Heitschmidt, R. K., and C. A. Taylor. 1991. Livestock production. In: R. K. Heitschmidt and J. W. Stuth [EDS.]. Grazing management. An ecological approach. Portland, OR, USA: Timber Press. p. 161-177.

Hester, A. J., I. J. Gordon, G. J. Baillie, and E. Tappin. 1999. Foraging behavior of sheep and red deer within naural heather/grass mosaics. Journal of Applied Ecology 36:133-146.

Hewitson, L., B. Dumont, and I. J. Gordon. 2005. Response of foraging sheep to variability in the spatial distribution of resources. Animal Behaviour 69:1069-1076.

Hickman, K. R., D. C. Hartnett, R. C. Cochran, and C. E. Owensby. 2004. Grazing management effects on plant species diversity in tallgrass prairie. Journal of Range Management 57:58-65.

Holechek, J. L., R. D. Pieper, and C. H. Herbel. 1995. Range management. Principles and practices. Englewood Cliffs, NJ, USA: Prentice Hall. 526 p.

Howery, L. D., D. W. Bailey, G. B. Ruyle, and W. J. Renken. 2000. Cattle use visual cues to track food locations. Applied Animal Behaviour Science 67:1-14.

Hunt, L. P., S. Petty, R. Cowley, A. Fisher, A. J. Ash, and N. MacDonald. 2007. Factors affecting the management of cattle grazing distribution in northern Australia: preliminary observations on the effect of paddock size and water points. Rangeland Journal 29:169-179. 
Jacobo, E. J., A. M. Rodríguez, N. Bartoloni, and V. Deregibus. 2006. Rotational grazing effects on rangeland vegetation at a farm scale. Rangeland Ecology \& Management 59:249-257.

Jentsch, A., J. Kreyling, and C. Beierkuhnlein. 2007. A new generation of climatechange experiments: events, not trends. Frontiers in Ecology and the Environment 5:365-374.

Jutila, H. M., and J. B. Grace. 2002. Effects of disturbance on germination and seedling establishment in a coastal prairie grassland: a test of the competitive release hypothesis. Journal of Ecology 90:291-302.

Kothmann, M. M., and R. T. Hinnant. 1994. The grazing manager. College Station, TX, USA: Texas Agricultural Experiment Station. $82 \mathrm{p}$.

KSIKSI, T., AND E. A. LACA. 2000. Can social interactions affect food searching efficiency of cattle? Rangeland Journal 22:235-242.

LACA, E. A. 1998. Spatial memory and food searching mechanisms of cattle. Journal of Range Management 51:370-378.

LACA, E. A. 2008. Foraging in a heterogeneous environment: intake and diet choice. In: H. H. T. Prins and F. van Langevelde [EDS.]. Resource ecology: spatial and temporal dynamics of foraging. Dordrecht, The Netherlands: Springer. $p$. 81-100.

LACA, E. A., AND I. M. ORTEGA. 1995. Integrating foraging mechanisms across spatial and temporal scales. In: N. E. West [ED.]. Fifth International Rangeland Congress. Salt Lake City, Utah, USA: Society for Range Management. p. 129-132.

Marotti, D. M., G. P. Cosgrove, D. F. Chapman, A. J. Parsons, A. R. Egan, and C. B. Anderson. 2002. Growing grass and clover separately allows animals to sustain a high nutrient intake. Proceedings of the New Zealand Society of Animal Production 62:163-166.

Milne, B. T., M. G. Turner, A. J. Wiens, and A. R. Johnson. 1992. Interactions between the fractal geometry of landscapes and allometric herbivory. Theoretical Population Biology 41:337-353.

Noy-MelR, I. 1975. Stability of grazing systems: an application of predator-prey graphs. Journal of Ecology 63:459-481.

O'Neill, R. V., R. H. Gardner, B. T. Milne, M. G. Turner, and B. Jackson. 1991. Heterogeneity and spatial hierarchies. In: J. Kolasa and S. T. A. Pickett [EDs.]. Ecological heterogeneity. New York, NY, USA: Springer-Verlag. p. 85-96.

Parsons, A. J., And B. Dumont. 2003. Spatial heterogeneity and grazing processes. Animal Research 52:161-179.

Parsons, A. J., S. Schwinning, and P. Carrere. 2001. Plant growth functions and possible spatial and temporal scaling errors in models of herbivory. Grass and Forage Science 56:21-34.

Prins, H. H. T., and F. van Langevelde. 2008. Assembling a diet from different places. In: H. H. T. Prins and F. van Langevelde [EDS.]. Resource ecology: spatial and temporal dynamics of foraging. Dordrecht, The Netherlands: Springer. $p$. 129-155.

Provenza, F. D. 1996. Acquired aversions as the basis for varied diets of ruminants foraging on rangelands. Journal of Animal Science 74:2010-2020.

Ritchie, M. E. 1998. Scale-dependent foraging and patch choice in fractal environments. Evolutionary Ecology 12:309-330.
RutTeR, S. M. 2006. Diet preference for grass and legumes in free-ranging domestic sheep and cattle: current theory and future application. Applied Animal Behaviour Science 97:17-35.

Rutter, S. M., J. E. Cook, K. L. Young, and R. A. Champion. 2005. Spatial scale of heterogeneity affects diet choice but not intake in beef cattle. In: J. A. Milne [ED.]. Pastoral systems in marginal environments. Glasgow, Scotland: Proceedings of a Satellite Workshop of the 20th International Grassland Congress; 3-6 July 2005. 127 p.

ScarneCCHiA, D. L., And M. M. Kothmann. 1982. A dynamic approach to grazing management terminology. Journal of Range Management 35:262-264.

Schwinning, S., And A. J. Parsons. 1996. Analysis of the coexistence mechanisms for grasses and legumes in grazing systems. Journal of Ecology 84:799-813.

Senft, R. L., M. B. Coughenour, D. W. Balley, L. R. Rittenhouse, O. E. Sala, and D. M. SWIFT. 1987. Large herbivore foraging and ecological hierarchies: landscape ecology can enhance traditional foraging theory. BioScience 37:789-799.

Sevi, A., A. Muscio, D. Dantone, V. Iascone, and F. D’Emilio. 2001. Paddock shape effects on grazing behavior and efficiency in sheep. Journal of Range Management 54:122-125.

SharRow, S. H. 1991. Tree planting pattern effects on forage production in a douglas-fir agroforest. Agroforestry Systems 16:167-175.

ShIYomI, M., AND S. KuBo. 1982. Spatial pattern changes of cattle population. Researches on Population Ecology 24:33-42.

Skolen, J. O., AND G. BLOSCHL. 2006. Sampling scale effects in random fields and implications for environmental monitoring. Environmental Monitoring and Assessment 114:521-552.

Soder, K. J., P. Gregorini, G. Scaglia, and A. J. Rook. 2009. Dietary selection of domestic grazing ruminants: current state of the knowledge. Rangeland Ecology \& Management 62:389-398.

Vallentine, J. F. 1990. Grazing management. San Diego, CA, USA: Academic Press. $533 \mathrm{p}$.

Villalba, J. J., and F. D. Provenza. 2002. Polyethylene gycol influences selection of foraging location by sheep consuming quebracho tannin. Journal of Animal Science 80:1846-1851.

Villalba, J. J., and F. D. Provenza. 2009. Learning and dietary choice in herbivores. Rangeland Ecology \& Management 62:399-406.

Walker, J., P. J. H. Sharpe, L. K. Penridge, and H. Wu. 1989. Ecological field theory-the concept and field tests. Vegetatio 83:81-95.

WalKeR, J. W., AND R. K. HeitschmidT. 1986. Effects of various grazing treatments on type and density of cattle trails. Journal of Range Management 39:428431.

WallisDeVries, M. F., E. A. Laca, and M. W. Demment. 1999. The importance of scale of patchiness for selectivity in grazing herbivores. Oecologia 121:355-363.

Weber, G. E., F. Jeltsch, N. Van Rooyen, and S. J. Milton. 1998. Simulated long-term vegetation response to grazing heterogeneity in semi-arid rangelands. Journal of Applied Ecology 35:687-699.

Westoby, M., B. WalkeR, and I. Noy-MeiR. 1989. Opportunistic management for rangelands not at equilibrium. Journal of Range Management 42:266-274. 